\title{
Implant-Supported Restoration with Straight and Angled Hybrid Abutments: Digital Image Correlation and 3D-Finite Element Analysis
}

\author{
Amir Mohidin Demachkia ${ }^{1}$ Luigi Giovanni Bernardo Sichi ${ }^{1}$ Jonas Vinicius Meireles Rodrigues ${ }^{10}$ \\ Lafayette Nogueira Junior $^{1}$ Rodrigo Máximo de Araújo ${ }^{1}$ Nathalia de Carvalho Ramos ${ }^{1,2}$ \\ Marco Antonio Bottino ${ }^{1}$ João Paulo Mendes Tribst ${ }^{3}$ (1)
}

${ }^{1}$ Department of Dental Materials and Prosthodontics, Institute of Science and Technology, São Paulo State University (UNSEP), São José dos Campos, São Paulo, Brazil

2 Department of Dentistry, University of Taubaté (UNITAU), Taubaté, Brazil

${ }^{3}$ Department of Dental Materials, Academic Centre for Dentistry Amsterdam (ACTA), University of Amsterdam and Vrije Universiteit Amsterdam, Amsterdam, the Netherlands

Eur J Gen Dent 2022;11:23-31.
Address for correspondence Amir Mohidin Mohamed Demachkia, DDS, MSc, PhD student, São Paulo State University (Unesp), College of Dentistry, Pos-Graduate Program in Restorative Dentistry (Dental materials and Prosthodontic)., Av. Engenheiro Francisco José Longo,777, 12245000 São José dos Campos, São Paulo, Brazil (e-mail: amirdimashkieh@gmail.com).

\section{Abstract \\ Keywords \\ - finite element analysis \\ - abutment design \\ - implants \\ - digital image correlation}

Objective The aim of this study was to investigate the effect of the hybrid abutment with different angles ( 0 and 15 degrees) on the stress distribution and deformation on maxillary implant-supported fixed prosthesis, using digital image correlation (DIC) and finite element analysis (FEA).

Materials and Methods For DIC, two situations were considered: conventional straight implant placement and implant placement with 15 degrees inclination. Different zirconia mesostructures were milled, one straight and the other with a 15degree angulation to correct the implant positioning. Then, the zirconia mesostructures were cemented to the titanium base (Ti base), and both groups received a lithium disilicate crown. The DIC technique was performed to measure the deformation generated on the simulated bone surface ( $150 \mathrm{~N}$ loading). For the FEA (in silico), three-dimensional numerical models based on the in vitro setup were modeled using computer-aided design software. All materials were considered elastic, isotropic, and homogeneous. Comparison of both methods showed coherence between the in vitro and in silico results. The von-Mises stress of the implants, Ti base and screw, and the maximum principal stress in the mesostructure and crown were calculated for both conditions.

Results The overall surface deformation distributions determined by both techniques were considered similar allowing the model validation. The higher deformation was found in the cervical region with a higher magnitude for the angled hybrid abutment. The same pattern was observed in the stress fields regardless of the analyzed region and structure.
DOI https://doi.org/ $10.1055 / \mathrm{s}-0042-1744362$. ISSN 2320-4753. (c) 2022. The Author(s).

This is an open access article published by Thieme under the terms of the Creative Commons Attribution License, permitting unrestricted use, distribution, and reproduction so long as the original work is properly cited. (https://creativecommons.org/licenses/by/4.0/)

Thieme Medical and Scientific Publishers Pvt. Ltd., A-12, 2nd Floor, Sector 2, Noida-201301 UP, India 
Conclusion Based on this study, using an angled hybrid abutment to correct the implant positioning generated higher stress in the implant fixture, surrounding tissue, $\mathrm{Ti}$ base, screw, and crown. Therefore, the implant should be positioned axially, whenever possible, to reduce the mechanical complications.

\section{Introduction}

A lost tooth in the esthetic zone can be restored by different approaches such as implant placement, resin-bonded fixed dental prosthesis, or removable partial dentures. Dental implants became the primary treatment option to replace a missing tooth since it is a conservative treatment with a high survival rate. ${ }^{1,2}$ However, the long-standing success of implants in the esthetic zone is influenced by many factors, including implant position, fixture diameter, surgical procedure, soft tissue stability, abutment design, and restorative materials. ${ }^{3-5}$

Among the implant abutment materials, the titanium (Ti) abutment has shown long-term stability and biocompatibility. ${ }^{6}$ However, the esthetic needs of the anterior area dictated the use of metal-free instead of the Ti one, as the grayish shade of metallic abutment has been noticeable through the peri-implant soft tissue. ${ }^{1,5}$ As an alternative, the zirconia abutment is regularly used because it has strong mechanical properties, ${ }^{7}$ long-term stability, and biocompatibility.,9 The three mostly common types of zirconia abutments are (a) one-piece prefabricated abutments manufactured by the implant company, (b) one-piece customized abutment made by computer-aided design and computer-aided manufacturing (CAD/CAM), and (c) two-piece hybrid abutment made with a customized CAD/CAM ceramic mesostructure bonded on a prefabricated Ti base. ${ }^{10,11}$ The hybrid abutments were introduced to combine the benefits of having metal abutment/implant connection and providing an esthetic suprastructure. ${ }^{12,13}$ There is a consensus in the literature that the difference in the hardness of the materials at the implant-abutment connection zone in one-piece zirconia abutment (titanium-zirconia) leads to excessive wear at implant interface resulting in increase in the misfit and prosthetic complications. ${ }^{3,14,15}$

In addition to the abutment material and design, the correct implant position guided by the upcoming prosthetic restoration location has been emphasized to achieve proper esthetic and biological outcomes. ${ }^{16}$ However, the bone morphology in the anterior region of the maxilla may guide the implant placement in an inclined position. This inclined position can be corrected prosthetically using angled abutments. ${ }^{17}$ The consequences of the angled abutment on stress distribution in implant and bone have been investigated, ${ }^{17-22}$ where previous studies stated that angled abutments increased the stress around the bone and implant. ${ }^{19-22}$ However, there is a lack of data concerning angled hybrid abutment in prosthetic rehabilitation.

Therefore, the aim of this study was to investigate the effect of the two-piece hybrid zirconia abutment with different angles (axial and 15 degrees) on the stress distribution of a unitary maxillary implant using digital image correlation (DIC) and finite element analysis (FEA).

\section{Materials and Methods}

\section{Digital Image Correlation}

Resin Model Fabrication and Implant Placement

In the present study, the peri-implant tissue for the experimental model was standardized using polyurethane resin (Polyurethane F160 Axson, Cercy, France) with the following dimensions: $78 \times 45 \times 9.13 \mathrm{~mm}$ (length, height, and depth), respectively. Two blocks were designed according to the manufacturer recommendations. After the resin curing, the polyurethane surfaces were polished with sandpapers (\#220-\#600) (3M ESPE, St. Paul, Minnesota, United States) under constant water cooling. The upper surface of each block was drilled under constant water cooling using the surgical drills according to the manufacturer recommendations (Conexão Sistemas de Prótese, Arujá, Brazil). Two different inclinations have been considered. The first block received a straight implant, maintaining the block and the implant platform parallel to each other. The second block received a 15-degree inclined implant, in which the drilling was performed in 15 degrees. To standardize the implant placement angulation, an adjustable surveying table associated with handpiece was used. The proper drilling burs were connected vertically to the surveyor arm (-Fig. 1) with fixtures and squares that allowed the angle modification according to the groups design.

\section{Abutment Fabrication and Cementation}

After implant placement, the Ti bases (Conexão Sistemas de Prótese, Arujá, Brazil) were sandblasted with $50 \mu \mathrm{m}$ aluminum oxide $\left(\mathrm{Al}_{2} \mathrm{O}_{3}\right)$ and cleaned in an ultrasonic bath ( 5 minute with isopropyl alcohol). Then the prepared Ti surface received a layer of universal primer (Monobond N, Ivoclar Vivadent ACT, Benderstr, Liechtenstein) for 60 seconds. All Ti bases surfaces were gently dried with air, and the screw access holes were protected with a Teflon tape. Next, according to the manufacturer's recommendation, two zirconia mesostructures (VITA In-Ceram YZ, Vita Zhanfabrik, Bad Säckingen, Germany) were milled and sintered. For the inclined implant, the zirconia mesostructure was designed with 15 degrees of angulation to correct the implant positioning (-Fig. 2). To cement the zirconia mesostructure to the $\mathrm{Ti}$ base and create a hybrid abutment, the intaglio and external surface of the zirconia mesostructure were sandblasted with $50 \mu \mathrm{m}$ aluminum oxide $\left(\mathrm{Al}_{2} \mathrm{O}_{3}\right)$ and cleaned in an ultrasonic bath (5 minutes with isopropyl alcohol). Then, a universal primer (Monobond $\mathrm{N}$, Ivoclar Vivadent ACT, Benderstr, Liechtenstein) was applied for 60 seconds and gently dried with air to remove any excess. After surface treatment, a dual cure resin cement (Multilink $\mathrm{N}$ 


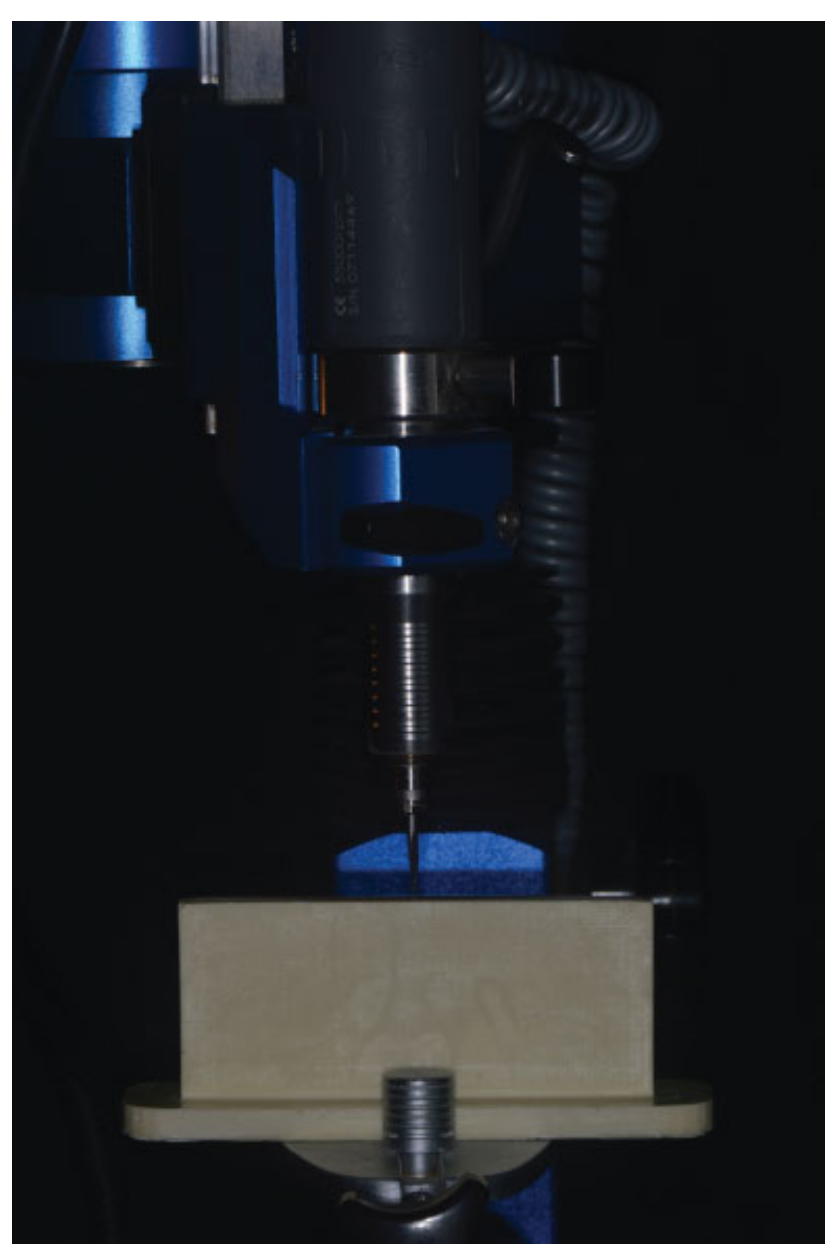

Fig. 1 Drilling of the resin block while the handpiece is mounted vertically to the surveyor table.

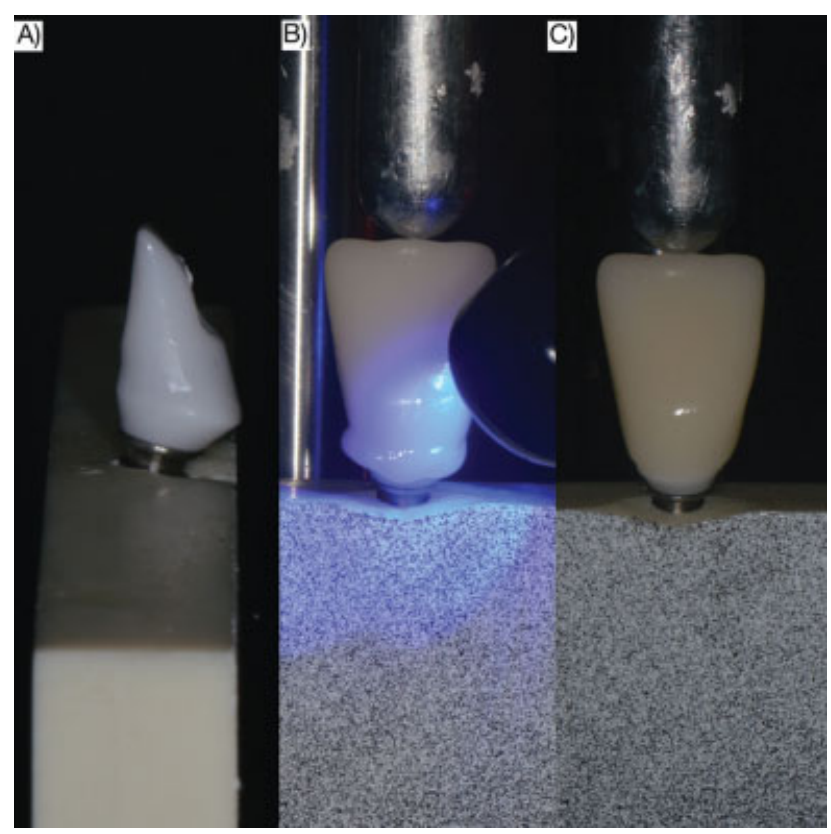

Fig. 2 (A) Lateral view: angled zirconia mesostructure after the cementation on titanium base. (B) Buccal view: lithium disilicate crown during cementation and photopolymerization. (C) Crown cemented on the angled hybrid abutment after excess cement removal. system pack; Ivoclar Vivadent ACT, Benderstr, Liechtenstein) was manipulated and applied on the Ti base and mesostructure intaglio surface, which was seated in position under a constant load of $0.8 \mathrm{~kg}$. After that, the cement excess was removed and light cured for 20 second using a LED light curing device (Bluephase N, Ivoclar Vivadent AG, Schaan, Liechtenstein). Next, the lithium disilicate all-ceramic crown (IPS e.max CAD, Ivoclar Vivadent AG, Schaan, Liechtenstein) were fabricated crystallized and polished. The crown's intaglio surface was etched by hydrofluoric acid gel 5\% (IPSCeramic Etching Gel, Ivoclar Vivadent, Schaan, Lichtenstein) for 20 seconds, washed with water, air dried and received the universal primer (Monobond N, Ivoclar Vivadent ACT, Benderstr, Liechtenstein) for 60 seconds. Finally, the crown was cemented with a resinous cement (Multilink N system pack; Ivoclar Vivadent ACT, Benderstr, Liechtenstein) following the manufacturer recommendations. The crown fabrication was similar for both conditions.

\section{Compressive Load Application and Image Correlation}

The DIC technique (in vitro) was performed to measure the deformation generated on the surface of the polyurethane block under compressive load application. ${ }^{23}$ A professional camera (Canon EOS Rebel T5 with Tamron $90 \mathrm{~mm} \mathrm{f/2.8} \mathrm{SP} \mathrm{VC}$ AF Macro-Lens) was used for capturing the image sequence. The camera had a resolution of 18.00 megapixels. Before the loading, the surface of the resin model facing the camera lens was individualized applying a fine layer of white spray. Then, a black spray was used to produce irregular-shaped speckles to track the image correlation analysis during the surface displacement. A compressive non-impact progressive $(0.1 \mathrm{~mm} / \mathrm{min})$ load of $150 \mathrm{~N}$ was applied using a universal testing machine (DL-1000, EMIC, São José dos Campos, Brazil). When the specimen was subjected to the loading, a special software package (Gom correlate, Vtech Consulting Ltda, São Paulo, Brazil) was used for image analysis.

To measure the generated deformation $(\mathrm{mm})$ on the block surface, sequential images were taken at a frequency of $1 \mathrm{~Hz}$ until the maximum load was reached. The first image was taken without loading, and the other photos were compared with the first image to calculate the displacements on the surface. The deformation was calculated from the displacement using image correlation software (GOM Correlate, Braunschweig, Germany). Before the image processing, the surface quality has been verified ( $\mathbf{- F i g . ~ 3 ) . 2 2 - 2 5}$

\section{Finite Element Analysis}

Three-dimensional numerical models based on the in vitro setup used in the DIC were modeled using CAD software (Rhinoceros version 4.0; McNeel North America, Seattle, Washington, United States). The models were then exported to computer-aided engineering software (Ansys Workbench 19.0 Ansys Inc., Canonsburg, Pennsylvania, United States) for the finite element simulation (in silico). The mechanical properties (Young's modulus and Poisson's ratio) of the simulated materials are summarized in - Table $\mathbf{1 .}$. $^{24,25}$

All materials were considered elastic, isotropic, and homogeneous. The loading configuration followed the same for the in vitro analysis with a compressive load of $150 \mathrm{~N}$. The contacts 

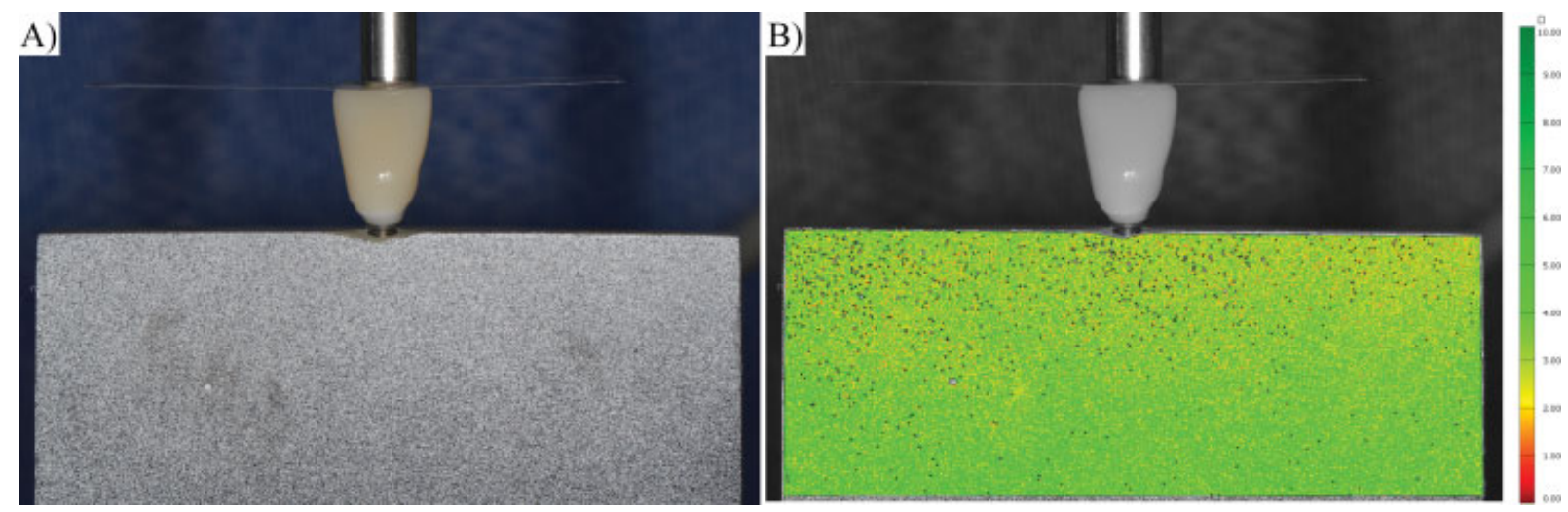

Fig. 3 (A) Isotropic substrate with prepared surface to perform the digital image correlation. (B) Measurement of the surface component quality prior to the calculation of the deformation results.

Table 1 Mechanical properties of the materials used in the computational analysis

\begin{tabular}{|l|l|l|}
\hline $\begin{array}{l}\text { Material/ } \\
\text { Structure }\end{array}$ & $\begin{array}{l}\text { Elastic modulus } \\
(\mathrm{MPa})\end{array}$ & $\begin{array}{l}\text { Poisson's } \\
\text { ratio }\end{array}$ \\
\hline Titanium & 110,000 & 0.30 \\
\hline Polyurethane & 3,600 & 0.30 \\
\hline Resin cement & 7,000 & 0.45 \\
\hline Zirconia & 210,000 & 0.33 \\
\hline Lithium disilicate & 89,000 & 0.31 \\
\hline
\end{tabular}

were set as bonded. A static linear structural analysis was performed. Both FEA models had similar mesh densities ( $0.3 \mathrm{~mm}$ each element) to increase the consistency and accuracy, with higher node density in the cervical region of the implant (mesh convergence test of 10\%). The three-dimen- sional models contained a total of 434,228 nodes with 211,236 quadratic elements and 448,334 nodes with 218,102 quadratic elements for the straight and angled model, respectively. The buccal surface of the polyurethane block has been measured according to the direction of deformation (vertical displacement), and the results were compared with the in vitro measurement. ${ }^{23,26}$ After comparison of coherence between the experimental(DIC) and virtual results (FEA), the von-Mises stress of the implants, Ti base, and fixation screw were calculated to predict failure region from these ductile solids. ${ }^{23}$ In addition, the Maximum Principal Stress in the mesostructure and crown were calculated for both models. ${ }^{12}$

\section{Results}

The overall surface deformation distributions determined by both techniques can be considered similar, as illustrated in

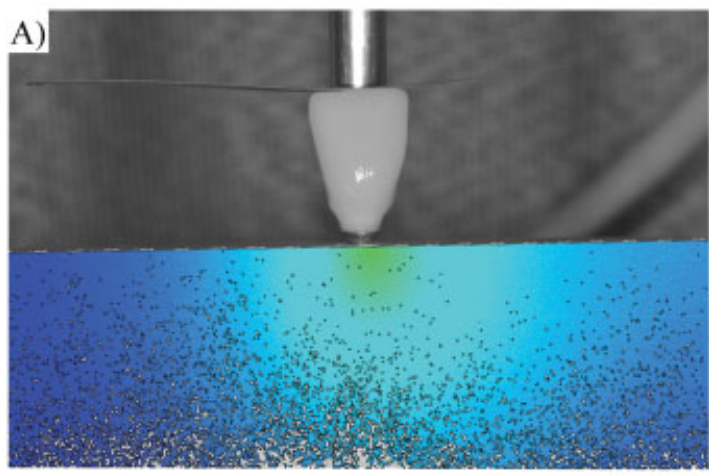

B)

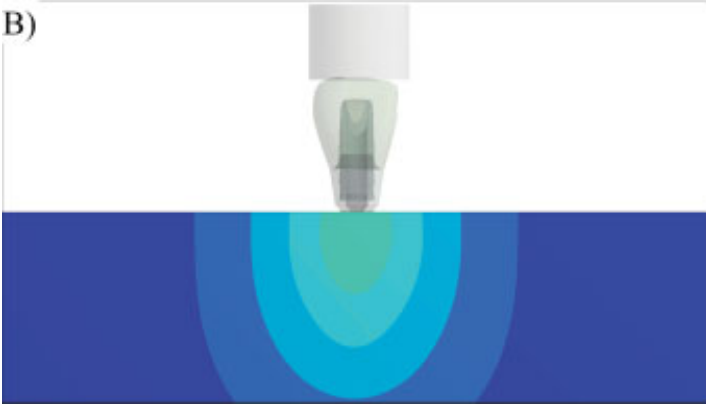

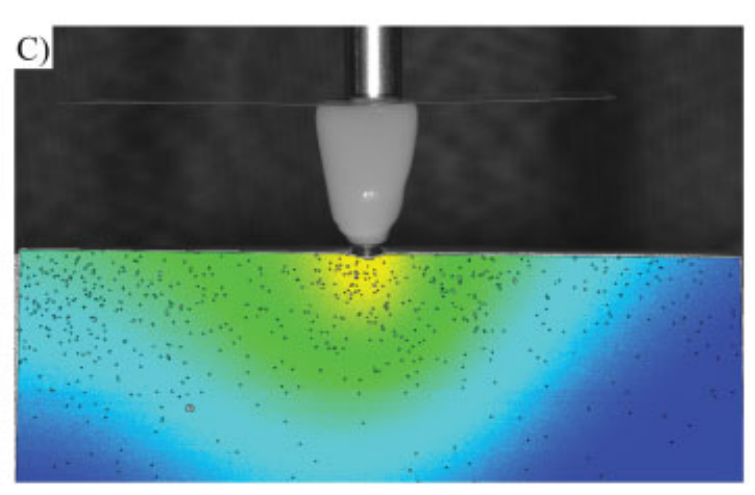

D)

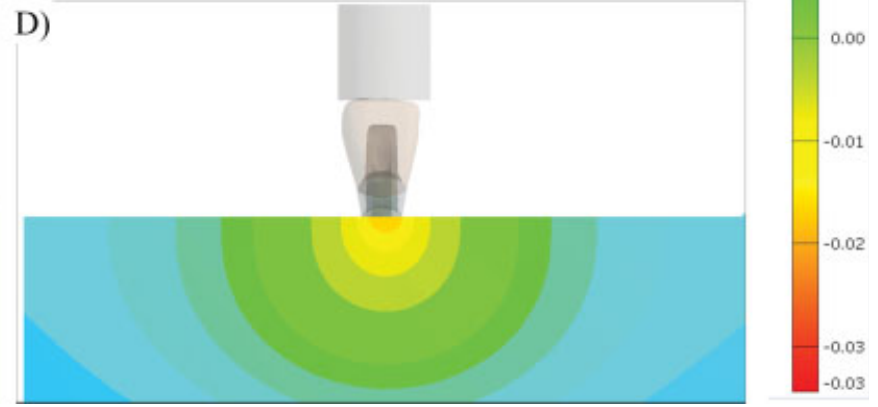

Fig. 4 Planar deformation measured in the vertical direction. (A) Axial implant with digital image correlation (DIC) results, (B) axial implant with finite element analysis (FEA) results, (C) nonaxial implant with DIC results, (D) nonaxial implant with FEA results. 
Table 2 Total deformation ( $\mathrm{mm}$ ) between both methods

\begin{tabular}{|l|l|l|l|}
\hline \multicolumn{2}{|l|}{ DIC } & \multicolumn{3}{l|}{ FEA } \\
\hline Straight & Angled & Straight & Angled \\
\hline 0.01 & 0.152 & 0.0116 & 0.173 \\
\hline
\end{tabular}

Abbreviations: DIC, digital image correlation; FEA, finite element analysis.

Table 3 von-Mises stress peak (MPa) for the analyzed structures for both designs

\begin{tabular}{|l|l|l|}
\hline Structure & Straight & Angled \\
\hline Implant & 38.7 & 62.9 \\
\hline Titanium base & 26.6 & 71.4 \\
\hline Fixation screw & 27.8 & 69.8 \\
\hline
\end{tabular}

-Fig. 4. As expected, higher deformation was found in the cervical region of the peri-implant tissue, in the central region with a higher magnitude for the angled abutment model. Both methods showed similar trends for the deformation; however, the FEA models predicted higher deformation magnitude $( \pm 14.6 \%)$ in comparison to DIC ( - Table 2$)$.

The magnitude over the entire region of interest as determined by both methods (DIC and FEA) for the simulated conditions is presented in - Table $\mathbf{3}$. In this sense, the FEA results are assumed as validated. Considering the stress fields in the structure of the implant, von-Mises stress revealed higher stress concentration in the implant with a nonaxial position (-Fig. 5). This same behavior can be observed in the Ti base (-Fig. 6), screw (-Fig. 7), and crown (-Fig. 8).

\section{Discussion}

Several bioengineering tools have been applied to evaluate the biomechanical behavior of implant supported prosthesis and surrounding tissue such as FEA, DIC, strain gauge measurement, and photoelastic analysis. ${ }^{20,23,27,28}$ However, every method presents limitations and there is no unique method that can achieve all the requirements for completely displaying the biomechanical behavior of an object subjected to a load. ${ }^{29}$ For that reason, the present study applied FEA and DIC to evaluate the influence of straight and angled hybrid abutments on the stress distribution of implant-supported restoration.

FEA is a numerical method applied to calculate the stress concentration within a simulated model when subjected to load. ${ }^{29}$ The advantages of FEA compared with other methods are the low cost, specimens standardization, ability to simulate complex scenarios, and predict the areas that might undergo failure. ${ }^{30}$

DIC is an optical method used to analyze the strain distribution on the surface of an object during load application. ${ }^{23}$ Unlike strain gauge tests, which are restricted to detect strains only at the contact area, DIC is a contactless test that provides

C)

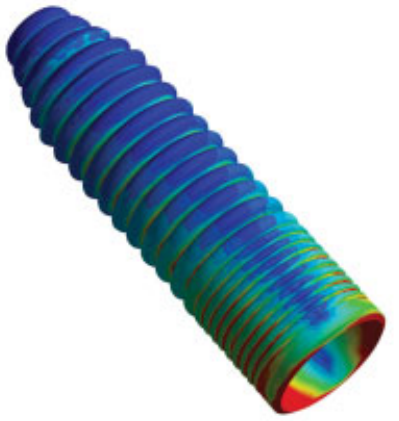

D)

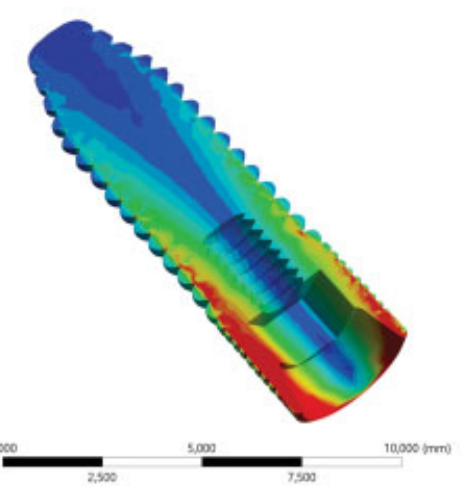

117,49

50

46,25

42,5

38,75

35

31,25

27,5

23,75

20

16,25

12,5

8,75

5

0,8276

Fig. 5 von-Mises stress concentration in the implants. ( $A$ and $B$ ) Axial implant and (C and D) nonaxial implant. 
A)

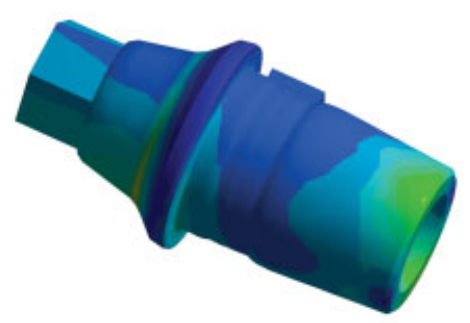

B)

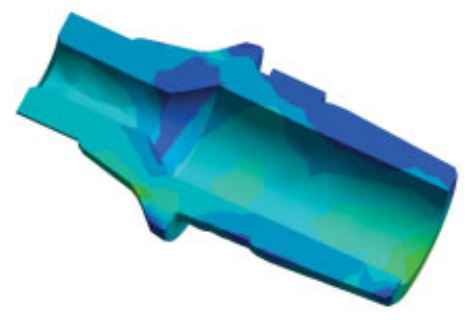

C)

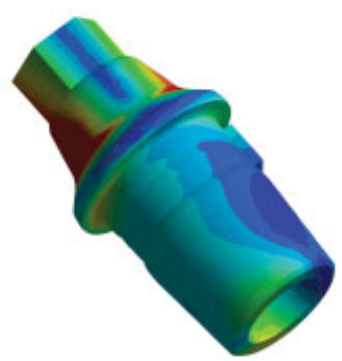

D)

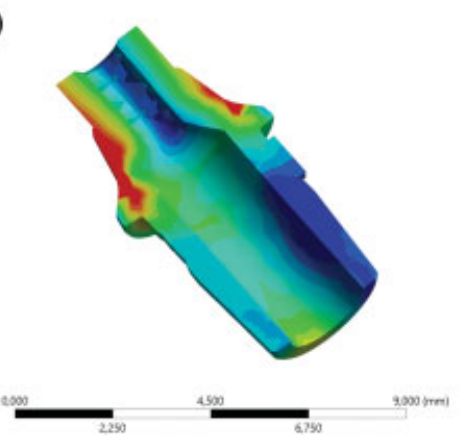

117,49
50
46,25
42,5
38,75
35
31,25
27,5
23,75
20
16,25
12,5
8,75
5
0,8276

Fig. 6 von-Mises stress concentration in the titanium bases. (A and B) Axial implant and (C and D) nonaxial implant.

A)

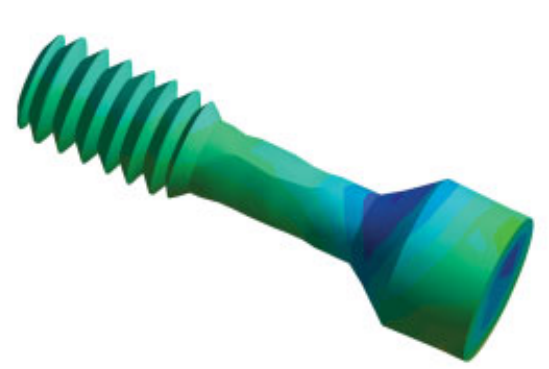

B)

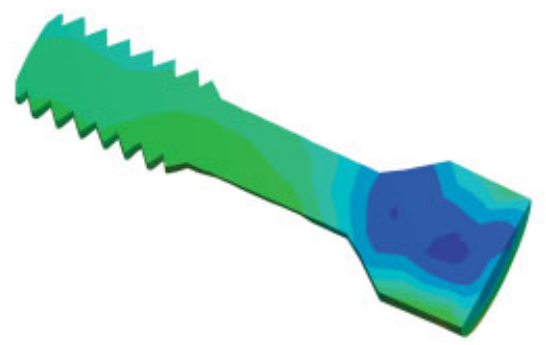

C)
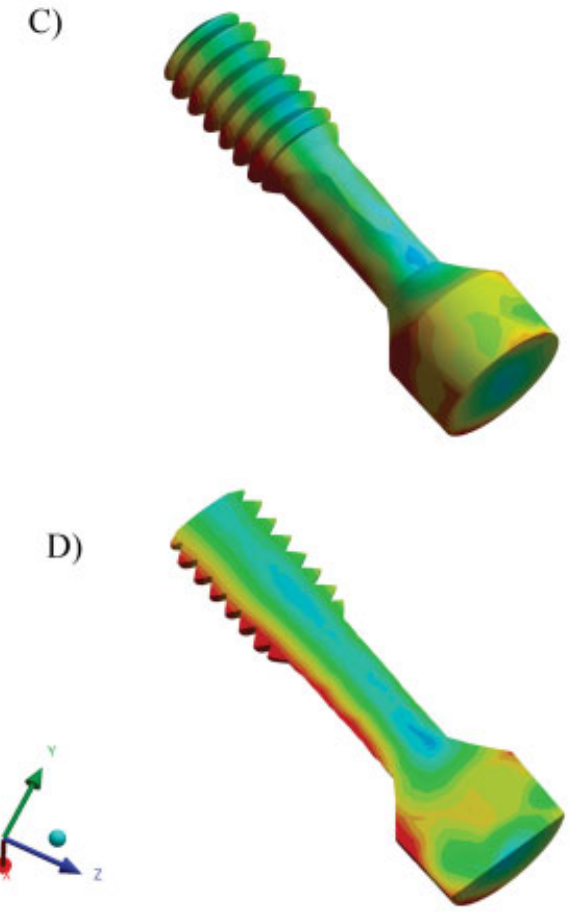

Fig. 7 von-Mises stress concentration in the screw. ( $A$ and $B$ ) Axial implant and (C and $D)$ nonaxial implant. 
A)

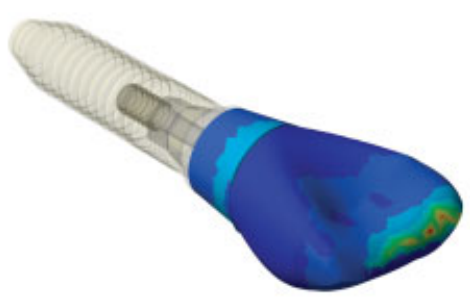

B)

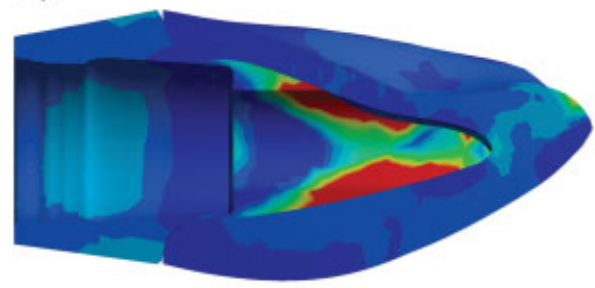

C)
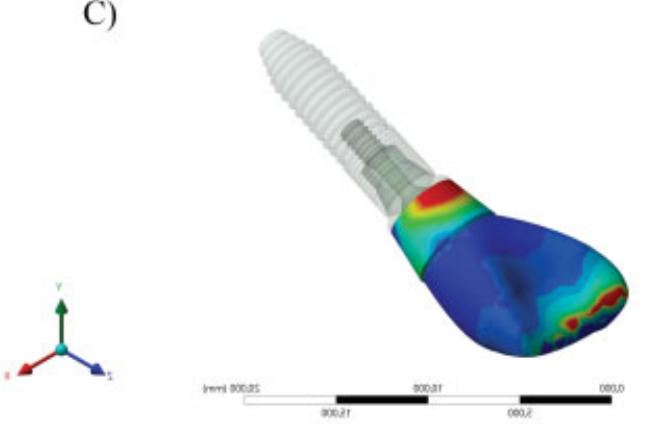

D)

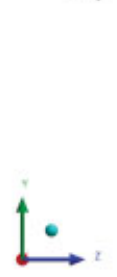

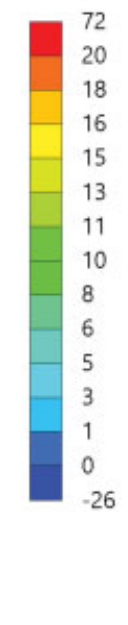

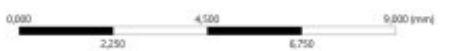

Fig. 8 Maximum principal stress concentration in the ceramic structures. (A and B) Axial implant and (C and D) nonaxial implant.

full field for the strain analysis. ${ }^{26}$ Therefore, it is a preferable method to verify and validate FEA models. ${ }^{29}$

Both methodologies showed that the nonaxial implant restored with angled hybrid abutments presented higher deformation compared with axial implant restored with a straight abutment. Although the FEA models predicted higher deformation magnitude $( \pm 14.6 \%)$ in comparison to DIC, this difference is considered acceptable and might be attributed to the inaccuracy in the mechanical material properties provided by the manufacturer ${ }^{23,26,31}$ and the numerical models simplifications. Thus, the similarity of the results between the in vitro test (DIC) and the in silico test (FE) guarantees a mutual validation of the technique and favors the recognition of internal stress results obtained by the FEA that cannot be observed with DIC. ${ }^{23,26}$

Implant failure are related to biological and mechanical complications. Nowadays, implant failures are predominantly related to mechanical complications rather than biological. Implant failure related to mechanical complications includes screw loosening, fracture of the screw, micromovements, abutment fracture, and fixture fracture. ${ }^{32,33}$ Considering the abutment material, prefabricated zirconia abutment led to plastic deformation at the Ti implant/abutment connection area $^{3,34-37}$ due to zirconia higher modulus of elasticity than Ti. Thus, the deformation will be concentrated in the implant surface. ${ }^{37}$ Lower fracture strength of one-piece prefabricated zirconia abutment when compared with hybrid abutment is another problem that has been reported. ${ }^{38-40}$ Therefore, hybrid abutment has gained popularity as they maintain stability at the implant/abutment connection area and provide highly esthetic superstructure. ${ }^{12,13,41}$

The function of the abutment screw is to be tightened to keep a stable union between the implant and abutment.
However, screw loosening is a critical mechanical complication that leads to micromovement and might end up with fracture. ${ }^{32}$ The higher amount of stress due to the off-axis load on the inclined implant suggests a higher chance for prosthetic complications such as screw loosening. ${ }^{42-44}$ Screw loosening can be explained by the present results which showed that the stress peak was located at the screw threads.

Regarding the results obtained in both tests, the high magnitude of deformation in the cervical area of the bone around the inclined abutment model is in accordance with the previous finite element studies. ${ }^{18,19,45}$ On the other hand, Saab et $\mathrm{al}^{14}$ found that strain and stresses on the bone around implant restored with angled abutment were similar in comparison with the straight one. Tian et $\mathrm{al}^{15}$ stated that inclined implants not placed in the ideal position and restored with angled abutment can show reduced strain on the surrounding bone. Although FEA is a beneficial bioengineering tool that aids in analyzing stress on the implant body, prosthetic parts, and surrounding bone, it was recommended to use more than one bioengineering tool or methodology to allow validated results. ${ }^{42,46}$

The present study analyzed only two-piece hybrid zirconia abutment with different angulation. Other abutment designs such as one-piece abutment with different angulations may present different results under loading. In this study, the load was applied on the incisal edge to keep the piston in a stable position during the in vitro load application. This load scenario represents the edge-to-edge occlusal relation that is not the common clinical scenario and must be considered as a study limitation.

In addition, the present study considered only one specimen mechanical behavior for the model validation, similar to other engineering procedures to validate biomedical, ${ }^{47}$ airplanes ${ }^{48}$ 
and even previous dental implants finite element models. ${ }^{23,26,42}$ Therefore, the present method is not considering the standard deviation from the different samples variation as conventional in vitro test for mean comparison between groups, but performing the results interpretation and conclusion in a valid numerical model. ${ }^{49}$ Moreover, the simulated bone was designed as a resinous isotropic structure rather than cortical and cancellous, which does not represent the clinical situation. Therefore, further studies are warranted, taking into account the described limitations.

\section{Conclusion}

Based on this study, using angled hybrid abutment to correct the implant inclination generated higher stress in the implant fixture, surrounding tissue, Ti base, screw, and crown. Therefore, the implant should be positioned axially, whenever possible, to reduce the mechanical complications.

\section{Funding \\ None declared. \\ Conflict of Interest \\ Non declared.}

\section{References}

1 Howe MS, Keys W, Richards D. Long-term (10-year) dental implant survival: a systematic review and sensitivity meta-analysis. J Dent 2019;84:9-21

2 Schimmel M, Srinivasan M, McKenna G, Müller F. Effect of advanced age and/or systemic medical conditions on dental implant survival: a systematic review and meta-analysis. Clin Oral Implants Res 2018;29(Suppl 16):311-330

3 Bottino MA, de Oliveira FR, Sabino CF, Dinato JC, Tribst JP. Survival rate and deformation of external hexagon implants with onepiece zirconia crowns. Metals (Basel) 2021;11(07):1068

4 Gomez-Meda R, Esquivel J, Blatz MB. The esthetic biological contour concept for implant restoration emergence profile design. J Esthet Restor Dent 2021;33(01):173-184

5 Adolfi D, Tribst JPM, Adolfi M, Dal Piva AMO, Saavedra GSFA, Bottino MA. Lithium disilicate crown, zirconia hybrid abutment and platform switching to improve the esthetics in anterior region: a case report. Clin Cosmet Investig Dent 2020;12:31-40

6 Pandoleon P, Bakopoulou A, Papadopoulou L, Koidis P. Evaluation of the biological behaviour of various dental implant abutment materials on attachment and viability of human gingival fibroblasts. Dent Mater 2019;35(07):1053-1063

7 Bottino MA, Rocha RFV, Anami LC, Özcan M, Marques de Melo R. Fracture of zirconia abutment with metallic insertion on anterior single titanium implant with internal hexagon: retrieval analysis of a failure. Eur J Prosthodont Restor Dent 2016;24(03):164-168

8 Kohal RJ, Weng D, Bächle M, Strub JR. Loaded custom-made zirconia and titanium implants show similar osseointegration: an animal experiment. J Periodontol 2004;75(09):1262-1268

9 Abrahamsson I, Berglundh T, Glantz PO, Lindhe J. The mucosal attachment at different abutments. An experimental study in dogs. J Clin Periodontol 1998;25(09):721-727

10 Naveau A, Rignon-Bret C, Wulfman C. Zirconia abutments in the anterior region: a systematic review of mechanical and esthetic outcomes. J Prosthet Dent 2019;121(05):775-781.e1

11 Nouh I, Kern M, Sabet AE, Aboelfadl AK, Hamdy AM, Chaar MS. Mechanical behavior of posterior all-ceramic hybrid-abutment- crowns versus hybrid-abutments with separate crowns-a laboratory study. Clin Oral Implants Res 2019;30(01):90-98

12 Tribst JP, Dal Piva AM, Anami LC, Borges AL, Bottino MA. Influence of implant connection on the stress distribution in restorations performed with hybrid abutments. J Osseointegration 2019;11 (03):507-512

13 Matos JD, Arcila LV, Ortiz LP, et al. Hybrid abutment during prosthetic planning and oral rehabilitation. Minerva Dent Oral Sci 2021;10.23736/S2724-6329.21.04479-4. Doi: 10.23736/s2724-6329. 21.04479-4

14 Saab XE, Griggs JA, Powers JM, Engelmeier RL. Effect of abutment angulation on the strain on the bone around an implant in the anterior maxilla: a finite element study. J Prosthet Dent 2007;97 (02):85-92

15 Tian K, Chen J, Han L, Yang J, Huang W, Wu D. Angled abutments result in increased or decreased stress on surrounding bone of single-unit dental implants: a finite element analysis. Med Eng Phys 2012;34(10):1526-1531

16 Schubert O, Schweiger J, Stimmelmayr M, Nold E, Güth J-F. Digital implant planning and guided implant surgery - workflow and reliability. Br Dent J 2019;226(02):101-108

17 Sousa MP, Tribst JPM, de Oliveira Dal Piva AM, Borges ALS, de Oliveira S, da Cruz PC. Capacity to maintain placement torque at removal, single load-to-failure, and stress concentration of straight and angled abutments. Int J Periodontics Restorative Dent 2019;39(02):213-218

18 Kao HC, Gung YW, Chung TF, Hsu ML. The influence of abutment angulation on micromotion level for immediately loaded dental implants: a 3-D finite element analysis. Int J Oral Maxillofac Implants 2008;23(04):623-630

19 Lin CL, Wang JC, Ramp LC, Liu PR. Biomechanical response of implant systems placed in the maxillary posterior region under various conditions of angulation, bone density, and loading. Int J Oral Maxillofac Implants 2008;23(01):57-64

20 Rodrigues VA, Tribst JP, Santis LR, Borges AL, Nishioka RS. Biomechanical effect of inclined implants in fixed prosthesis: strain and stress analysis. Rev Odontol UNESP 2018;47(04): 237-243

21 Rodrigues VA, Tribst JP, de Santis LR, de Lima DR, Nishioka RS. Influence of angulation and vertical misfit in the evaluation of micro-deformations around implants. Braz Dent Sci 2017;20(01): 32-39

22 Eger DE, Gunsolley JC, Feldman S. Comparison of angled and standard abutments and their effect on clinical outcomes: a preliminary report. Int J Oral Maxillofac Implants 2000;15(06): 819-823

23 Tribst JPM, Dal Piva AMO, Bottino MA, Nishioka RS, Borges ALS, Özcan M. Digital image correlation and finite element analysis of bone strain generated by implant-retained cantilever fixed prosthesis. Eur J Prosthodont Restor Dent 2020;28(01):10-17

24 Ausiello P, Tribst JPM, Ventre M, et al. The role of cortical zone level and prosthetic platform angle in dental implant mechanical response: a 3D finite element analysis. Dent Mater 2021;37 (11):1688-1697

25 Monteiro JB, Dal Piva AMO, Tribst JPM, Borges ALS, Tango RN. The effect of resection angle on stress distribution after root-end surgery. Iran Endod J 2018;13(02):188-194

26 Tiossi R, Vasco MA, Lin L, et al. Validation of finite element models for strain analysis of implant-supported prostheses using digital image correlation. Dent Mater 2013;29(07):788-796

27 Cavallaro J Jr, Greenstein G. Angled implant abutments: a practical application of available knowledge. J Am Dent Assoc 2011;142 (02):150-158

28 Cantó-Navés O, Marimon X, Ferrer M, Cabratosa-Termes J. Comparison between experimental digital image processing and numerical methods for stress analysis in dental implants with different restorative materials. J Mech Behav Biomed Mater 2021; 113:104092 
29 Karl M, Dickinson A, Holst S, Holst A. Biomechanical methods applied in dentistry: a comparative overview of photoelastic examinations, strain gauge measurements, finite element analysis and three-dimensional deformation analysis. Eur J Prosthodont Restor Dent 2009;17(02):50-57

30 Tribst JPM, Dal Piva AMO, Madruga CFL, et al. Endocrown restorations: Influence of dental remnant and restorative material on stress distribution. Dent Mater 2018;34(10):1466-1473

31 Berahmani S, Janssen D, Verdonschot N. Experimental and computational analysis of micromotions of an uncemented femoral knee implant using elastic and plastic bone material models. J Biomech 2017;61:137-143

32 El-Sheikh MAY, Mostafa TMN, El-Sheikh MM. Effect of different angulations and collar lengths of conical hybrid implant abutment on screw loosening after dynamic cyclic loading. Int J Implant Dent 2018;4(01):39

33 Shemtov-Yona K, Rittel D. An overview of the mechanical integrity of dental implants. BioMed Res Int 2015;2015:547384

34 Pereira PHS, Amaral M, Baroudi K, Vitti RP, Nassani MZ, SilvaConcílio LRD. Effect of implant platform connection and abutment material on removal torque and implant hexagon plastic deformation. Eur J Dent 2019;13(03):349-353

35 Yüzügüllü B, Avci M. The implant-abutment interface of alumina and zirconia abutments. Clin Implant Dent Relat Res 2008;10(02): 113-121

36 Stimmelmayr M, Sagerer S, Erdelt K, Beuer F. In vitro fatigue and fracture strength testing of one-piece zirconia implant abutments and zirconia implant abutments connected to titanium cores. Int J Oral Maxillofac Implants 2013;28(02):488-493

37 Stimmelmayr M, Edelhoff D, Güth J-F, Erdelt K, Happe A, Beuer F. Wear at the titanium-titanium and the titanium-zirconia implant-abutment interface: a comparative in vitro study. Dent Mater 2012;28(12):1215-1220

38 Gehrke P, Johannson D, Fischer C, Stawarczyk B, Beuer F. In vitro fatigue and fracture resistance of one- and two-piece CAD/CAM zirconia implant abutments. Int J Oral Maxillofac Implants 2015; 30(03):546-554

39 Sailer I, Asgeirsson AG, Thoma DS, et al. Fracture strength of zirconia implant abutments on narrow diameter implants with internal and external implant abutment connections: a study on the titanium resin base concept. Clin Oral Implants Res 2018;29 (04):411-423

40 Chun HJ, Yeo IS, Lee JH, et al. Fracture strength study of internally connected zirconia abutments reinforced with titanium inserts. Int J Oral Maxillofac Implants 2015;30(02):346-350

41 Pjetursson BE, Zarauz C, Strasding M, Sailer I, Zwahlen M, Zembic A. A systematic review of the influence of the implant-abutment connection on the clinical outcomes of ceramic and metal implant abutments supporting fixed implant reconstructions. Clinl Oral implants Res 2018;29:160-183

42 Datte CE, Tribst JP, Dal Piva AO, et al. Influence of different restorative materials on the stress distribution in dental implants. J Clin Exp Dent 2018;10(05):e439-e444

43 Morsch CS, Rafael CF, Dumes JFM, Juanito GMP, Souza JGOd, Bianchini MA. Failure of prosthetic screws on 971 implants. Braz J Oral Sci 2015;14:195-198

44 Ha CY, Lim YJ, Kim MJ, Choi JH. The influence of abutment angulation on screw loosening of implants in the anterior maxilla. Int J Oral Maxillofac Implants 2011;26(01):45-55

45 Clelland NL, Lee JK, Bimbenet OC, Brantley WA. A three-dimensional finite element stress analysis of angled abutments for an implant placed in the anterior maxilla. J Prosthodont 1995;4(02): 95-100

46 Tribst JP, Rodrigues VA, Dal Piva AO, Borges AL, Nishioka RS. The importance of correct implants positioning and masticatory load direction on a fixed prosthesis. J Clin Exp Dent 2018;10(01): e81-e87

47 Bola M, Simões J, Ramos A. Finite element model validation based on an experimental model of the intact shoulder joint. Med Eng Phys 2021;87:1-8

48 Miller EJ, Holguin AC, Cruz J, Lokos WA. Strain Gage load calibration of the wing interface fittings for the adaptive compliant trailing edge flap flight test. In: 52 nd Aerospace Sciences Meeting. Reston, Virginia: American Institute of Aeronautics and Astronautics; 2014

49 Bathe K-J. Finite Element Procedures in Engineering Analysis. Old Tappan, NJ: Prentice Hall; 1982 